\title{
Peripheral neurotoxic effects of cisplatin on rats and treatment with rutin
}

\author{
Hasan Yaşar ${ }^{1, A-F}$, Alevtina Ersoy ${ }^{1, B-D, F}$, Ferda Keskin Cimen ${ }^{2, B, D, F}$, \\ Renad Mammadov ${ }^{3, B, D, F}$, Nezahat Kurt ${ }^{4, A, B, E, F}$, Yusuf Kemal Arslan ${ }^{5, C, D, F}$ \\ ${ }^{1}$ Department of Neurology, Erzincan University, Mengücek Gazi Research and Training Hospital, Turkey \\ ${ }^{2}$ Department of Pathology, Erzincan University, Mengücek Gazi Research and Training Hospital, Turkey \\ ${ }^{3}$ Department of Pharmacology, Faculty of Medicine, Erzincan University Hospital, Turkey \\ ${ }^{4}$ Department of Biochemistry, Faculty of Medicine, Erzurum University Hospital, Turkey \\ ${ }^{5}$ Department of Biostatistics, Faculty of Medicine, Erzincan University Hospital, Turkey \\ A - research concept and design; $\mathrm{B}$ - collection and/or assembly of data; $\mathrm{C}$ - data analysis and interpretation; \\ $D$ - writing the article; $E$ - critical revision of the article; $F$ - final approval of the article
}

\section{Address for correspondence \\ Hasan Yaşar}

E-mail: yasar_hsan@hotmail.com

\section{Funding sources}

None declared

\section{Conflict of interest}

None declared

Received on May 31, 2018

Reviewed on August 14, 2018

Accepted on August 18, 2019

Published online on November 25, 2019

Cite as

Yaşar H, Ersoy A, Keskin Cimen F, Mammadov R,

Kurt N, Arslan YK. Peripheral neurotoxic effects of cis-

platin on rats and treatment with rutin. Adv Clin Exp Med.

2019;28(11):1537-1543. doi:10.17219/acem/111819

DOI

10.17219/acem/111819

\section{Copyright}

Copyright by Author(s)

This is an article distributed under the terms of the

Creative Commons Attribution Non-Commercial License

(http://creativecommons.org/licenses/by-nc-nd/4.0/)

\begin{abstract}
Background. Cisplatin, used in cancer treatment, has toxic and apoptotic effects on the peripheral nervous system. Rutin, also known as vitamin P, has antioxidant and antiapoptotic activity.

Objectives. The purpose of this study was to investigate the biochemical and histopathologic efficacy of rutin on neurotoxic and apoptotic effects caused by cisplatin in the peripheral nervous system.

Material and methods. Twenty-four albino Wistar male rats were divided into the following 4 groups: control group (CG), only cisplatin-injected group (CIS), cisplatin and rutin $50 \mathrm{mg} / \mathrm{kg}$ (RG-50)-injected group, and cisplatin and rutin $100 \mathrm{mg} / \mathrm{kg}$ (RG-100)-injected group. Analyses were performed on sciatic nerve tissue of experimental animals. Analyses of malondialdehyde (MDA), total glutathione (tGSH), glutathione reductase (GSHRd), glutathione-s-transferase (GST), and superoxide dismutase (SOD) were performed. Caspase-3 expression in nerve tissue was also investigated. The analyzed groups were compared with CG.
\end{abstract}

Results. Biochemical investigation shows that there is a statistically significant difference between CG and only CIS and RG-50. Control group and RG-100 were found to be similar. Cisplatin-induced changes were observed in histopathological analysis of the nerve tissue. The RG-100 and CG were found to be similar. The caspase-3 expression in the neural tissue was compared between groups. Control group and CIS were found to be different. Control group and RG-100 were found to be similar.

Conclusions. Antioxidant and antiapoptotic effectiveness of rutin was detected against the toxic effects caused by cisplatin in the peripheral nerve tissue.

Key words: apoptosis, antioxidants, cisplatin, rutin, caspase-3 


\section{Introduction}

Cisplatin is an old and important drug used in the treatment of cancer. It is used in many types of cancer. The main side effects are ototoxicity, nephrotoxicity and neurotoxicity, which are dose-limiting. Cisplatin causes peripheral neuropathy due to its toxic effect on peripheral nerve dorsal root ganglia. ${ }^{1}$ The occurrence of peripheral neuropathy causes a reduction in dose and early termination of treatment. Pathophysiological mechanisms leading to the formation of peripheral neuropathies are oxidative damage, inflammation, mitochondrial dysfunction, DNA damage, and apoptosis. ${ }^{2}$ Due to the absence of protection, like a bloodbrain barrier in central nervous system, peripheral nerves can easily be exposed to toxic effects. Patients complaining of numbness in the form of glove-socks, clinical absence or reduction of deep tendon reflexes, decrease of distal vibration, and proprioceptive sensations are observed. Morphologic changes and deterioration of mitochondrial DNA transcription and replication in neuronal mitochondria were demonstrated during cisplatin treatment. Energy deficit, which is one of the causes of peripheral neuropathy, can take place due to the deterioration of mitochondrial functions. Cisplatin leads to an increased level of reactive oxygen species (ROS), which, in turn, causes an increase in lipid peroxidation and a decrease in catalase and glutathione peroxidase activity, consequently leading to apoptosis due to an excessive increase in caspase- 3 expression. ${ }^{3}$

Oxidative stress stems from an insufficient detoxification of the biological system with increased ROS. Lipid peroxidation causes many compounds that are harmful to the cells. Arachidonic acid is an omega- 6 fatty acid that can be a source of hydrogen atoms for free radicals found in cell membranes. Malondialdehyde (MDA) is the major metabolite of arachidonic acid and a reliable biomarker of oxidative stress. Following the MDA level makes it is possible to follow also lipid peroxidation. The MDA level in blood plasma or tissue homogenates is one of the most useful factors in determining oxidative stress. ${ }^{4}$ Neurotoxicity has been associated with increased oxidative stress and decreased glutathione levels. Glutathione-s-transferase (GST) is a key enzyme in the defense of the cells against oxidative stress. The main function of GST is detoxification of ROS and other oxidative stress products through reduced glutathione. ${ }^{5}$ Glutathione reductase (GSHRd) is responsible for providing reduced glutathione, which is one of the most important factors in controlling intracellular ROS. It acts as an electron donor for antioxidant enzymes, such as GST. ${ }^{6}$ Superoxide radical anion forms from free radicals in the cell after aerobic respiration. Superoxide dismutase (SOD) transforms and consumes this formed radical. As a result, it is important to prevent oxidative stress. ${ }^{7}$ Oxidative stress can lead to apoptosis by activating the pathways. Apoptosis occurs after the activation of caspase enzymes. Caspase- 3 is at the end of this path and can be activated by both the internal and external pathway. For this reason, caspase- 3 may be considered to reflect the general characteristics of apoptosis. ${ }^{8}$

Rutin is an important flavonoid that is consumed in a daily diet and is found in many vegetables and fruits. It is also known as vitamin $\mathrm{P}$. The protective and antiinflammatory activity of rutin has been shown in many studies. It inhibits the peroxidation of low-density lipoprotein (LDL). It also reduces oxidative stress and inflammation and normalizes caspase- 3 expression. ${ }^{9}$ Rutin, due to its free radical consumer efficacy, prevents the toxic effects of oxidative stress by inhibiting the effects of ROS and shows neuroprotective activity. ${ }^{10}$

The toxic effect of cisplatin on the peripheral nerves was investigated in many studies. However, there was no study showing the protective effect of rutin in preventing these side effects of cisplatin. Therefore, the aim of this study was to investigate the neuroprotective and antiapoptotic effectiveness of different doses of rutin on the side effects of cisplatin in biochemical and histopathologic rat experiments. For this purpose, MDA, GST, GSHRd, and SOD levels, and caspase-3 expression were measured in experimental animals and compared with the control group.

\section{Material and methods}

Animal experiments were performed in accordance with the National Guidelines for the Use and Care of Laboratory Animals and were approved by the local animal ethics committee of Atatürk University, Erzurum, Turkey (Ethics Committee approval No. 1700238627 dated August 25, 2017).

\section{Study animals}

A total of 24 albino Wistar male rats weighing 250$265 \mathrm{~g}$ were used in the study. The animals were obtained from Atatürk University Medical Experimental Application and Research Center. Before the experiments, the animals were housed and fed in groups at room temperature $\left(22^{\circ} \mathrm{C}\right)$ for 7 days under appropriate conditions.

\section{Chemical substances}

The following chemical substances were used for the experiments: cisplatin vials $(50 \mathrm{mg} / 100 \mathrm{~mL}$; Cisplatin-Ebewe) were provided by Liba Laboratuarları A.Ş. (Istanbul, Turkey), rutin (in tablet form) was provided by Solgar America (Leonia, USA) and thiopental sodium was obtained from IE Ulagay Ilac Sanayii Turk A.S. (Istanbul, Turkey).

\section{Experiment groups and procedure}

The animals were divided into only cisplatin-treated group (CIS), cisplatin $+50 \mathrm{mg} / \mathrm{kg}$ rutin (RG-50)-treated group, cisplatin $+100 \mathrm{mg} / \mathrm{kg}$ rutin (RG-100)-treated group, and control group without any treatment (CG). 
In the course of the experiment, RG-50 $(n=6)$ received $50 \mathrm{mg} / \mathrm{kg}$ of rutin and $\mathrm{RG}-100$ group $(\mathrm{n}=6)$ received $100 \mathrm{mg} / \mathrm{kg}$ of rutin by oral gavage. In previous experimental studies, these doses of rutin were found to be effective. ${ }^{11}$ For CIS $(n=6)$ and CG $(n=6)$, only distilled water was intraperitoneally (ip.) injected as solvent in the same volume $(0.5 \mathrm{~mL})$. One hour after rutin and distilled water, cisplatin $5 \mathrm{mg} / \mathrm{kg}$ was administered ip. to all groups, except CG. It is a common practice that drugs protecting tissues against the toxic effect of cisplatin are given to experimental animals $1 \mathrm{~h}$ before cisplatin. ${ }^{12}$ Rutin and distilled water were administered once a day for 8 days. Cisplatin was administered every 2 days for 8 days.

At the end of this period, the sciatic nerve was removed from the animals, which were killed with a high dose of thiopental sodium. The attained samples were investigated biochemically and histopathologically. All results obtained from the experiments were compared with CG.

\section{Malondialdehyde analysis}

For the MDA measurement, we adhered to the method used by Ohkawa et al. ${ }^{13}$ This method is based on the spectrophotometric measurement of the absorbance of the pink complex formed by MDA with thiobarbituric acid (TBA) at high temperature $\left(95^{\circ} \mathrm{C}\right)$ and $532 \mathrm{~nm}$ wavelength. The homogenates were centrifuged at 5,000 g for $20 \mathrm{~min}$ and these supernatants were used to determine the amount of MDA. Briefly, $250 \mu \mathrm{L}$ of homogenate, $100 \mu \mathrm{L}$ of $8 \%$ sodium dodecyl sulfate (SDS), $750 \mu \mathrm{L}$ of $20 \%$ acetic acid, $750 \mu \mathrm{L}$ of $0.08 \% \mathrm{TBA}$, and $150 \mu \mathrm{L}$ of purified water were vortexed into the capped test tubes. The mixture was allowed to incubate at $100^{\circ} \mathrm{C}$ for $60 \mathrm{~min}$, after which $2.5 \mathrm{~mL}$ of n-butanol was added and spectrophotometric measurements were taken. The resulting red color quantities were read at $532 \mathrm{~nm}$ using $3 \mathrm{~mL}$ cuvettes, and the MDA concentration of the samples was determined by taking the dilution coefficients into account using the standard graphic generated with the previously prepared MDA stock solution.

\section{Total glutathione analysis}

The amount of GSH in the total homogenate was measured according to the method used by Sedlak and Lindsay, with some modifications. ${ }^{14}$ The sample was weighed and homogenized in $2 \mathrm{~mL}$ of $50 \mathrm{mmol} / \mathrm{L}$ of Tris- $\mathrm{HCl}$ buffer containing $20 \mathrm{mmol} / \mathrm{L}$ of ethylenediaminetetraacetic acid (EDTA) and $0.2 \mathrm{mmol} / \mathrm{L}$ of sucrose at $\mathrm{pH} 7.5$. The homogenate was immediately precipitated with $0.1 \mathrm{~mL}$ of $25 \%$ trichloroacetic acid, and the precipitate was removed after centrifugation at 4,200 rpm for $40 \mathrm{~min}$ at $4^{\circ} \mathrm{C}$, and the supernatant was used to determine GSH level. A total of $1,500 \mu \mathrm{L}$ of measurement buffer $(200 \mathrm{mmol} / \mathrm{L}$ Tris $-\mathrm{HCl}$ buffer containing $0.2 \mathrm{mmol} / \mathrm{L}$ of EDTA at $\mathrm{pH} 7.5), 500 \mu \mathrm{L}$ of supernatant, $100 \mu \mathrm{L}$ of 5,5-dithiobis (2-nitrobenzoic acid), also known as Ellman's reagent (DTNB) $(10 \mathrm{mmol} / \mathrm{L})$, and 7,900 $\mu \mathrm{L}$ of methanol were added to a tube, vortexed and incubated for $30 \mathrm{~min}$ in $37^{\circ} \mathrm{C}$. The DTNB was used as an chromogen and it formed a yellow-colored complex with sulfhydryl groups. The absorbance was measured at $412 \mathrm{~nm}$, using a spectrophotometer (Beckman DU 500; Beckman Coulter, Brea, USA). The standard curve was obtained using a reduced glutathione.

\section{Glutathione reductase analysis}

Glutathione reductase activity was determined spectrophotometrically by measuring the rate of NADPH oxidation at $340 \mathrm{~nm}$ according to Carlberg and Mannervik method. ${ }^{15}$ After tissue homogenization, supernatant was used for GSHRd measurement. After the NADPH and glutathione disulfide (GSSG) addition, chronometer was on and absorbance was measured with spectrophotometric methods for $5 \mathrm{~min}$ by 30 -minute intervals at $340 \mathrm{~nm}$.

\section{Glutathione-s-transferase activity}

Glutathione-s-transferase activity was performed according to the method used by Habig and Jakoby. ${ }^{16}$ Briefly, the activity of the enzyme was assayed spectrophotometrically at $340 \mathrm{~nm}$ in a $4 \mathrm{~mL}$ cuvette containing $0.1 \mathrm{M}$ of PBS (pH 6.5), $30 \mathrm{mM} \mathrm{GSH}, 30 \mathrm{mM}$ of 1-chloro-2,6-dinitrobenzene and tissue homogenate.

\section{Superoxide dismutase analysis}

Superoxide dismutase analysis performed according to the method used by Sun et al. ${ }^{17}$ When xanthine is converted into uric acid by xanthine oxidase, SOD forms. If nitro blue tetrazolium (NBT) is added to this reaction, SOD reacts with NBT and a purple-colored formazan dye occurs. The sample was weighed and homogenized in $2 \mathrm{~mL}$ of $20 \mathrm{mmol} / \mathrm{L}$ phosphate buffer containing $10 \mathrm{mmol} / \mathrm{L}$ of EDTA at $\mathrm{pH}$ 7.8. The sample was centrifuged at 6,000 rpm for $10 \mathrm{~min}$ and then the brilliant supernatant was used as an assay sample. The measurement mixture containing $2,450 \mu \mathrm{L}$ of measurement mixture $(0.3 \mathrm{mmol} / \mathrm{L}$ of xanthine, $0.6 \mathrm{mmol} / \mathrm{L}$ of EDTA, $150 \mu \mathrm{mol} / \mathrm{L}$ of NBT, $0.4 \mathrm{~mol} / \mathrm{L}$ of $\mathrm{Na}_{2} \mathrm{CO}_{3}, 1 \mathrm{~g} / \mathrm{L}$ bovine serum albu$\min$ ), $500 \mu \mathrm{L}$ of supernatant, and $50 \mu \mathrm{L}$ of xanthine oxidase (167 U/L (unit /liter)) was vortexed. Then, it was incubated for $10 \mathrm{~min}$. At the end of the reaction, formazan appeared. The absorbance of the purple-colored formazan was measured at $560 \mathrm{~nm}$. As more of the enzyme exists, the least $\mathrm{O} 2^{-}$radical that reacts with $\mathrm{NBT}$ occurs.

\section{Histopathologic analyses}

The sciatic nerve tissue attained from the rats was fixed in $10 \%$ formalin solution for $24 \mathrm{~h}$. Four micron thick sections were obtained from the paraffin blocks after routine 
tissue procedure and stained with hematoxylin and eosin (H\&E). All sections were evaluated using a light microscope (Olympus BX 52; Olympus, Tokyo, Japan) by a pathologist who did not know which treatment protocol was applied to samples.

\section{Immunohistochemical procedures}

For immunohistochemical staining, primary antibodies of caspase-3 antibody Cat: RB-1197-P0, Lot: CPP32, Ab-4 (Santa Cruz Biotechnology, Dallas, USA, TX:1/100, and Cell Signaling Technology Inc, Danvers, USA) were used. Sections were stained using a fully automated immunohistochemistry (IHC) device (Leica Bond-Max; Leica Biosystems, Melbourne, Australia). After being processed in the IHC device, sections were dehydrated through a graded series of ethanol to xylene and enclosed with a mounting medium (Entellan; Merck Millipore, Darmstadt, Germany). From the rat sciatic nerve samples incubated in $10 \%$ formalin solution for IHC processing, $4 \mu \mathrm{m}$ thick sections were cut on a positively charged microscope slide. The results of the analysis under Olympus BX51 microscope were evaluated based on the caspase- 3 staining of the sciatic nerve using the grading system described below. In this evaluation, diffuseness and intensity were considered separately. Diffuseness represents the areas the dye can be found and the intensity represents the intensity of coloration. For diffuseness, grade I represent coloration in less than 10\%, grade II represents coloration $10-50 \%$, and grade III represents coloration in more than $50 \%$ of the cells. For intensity, grade I represent mild, grade II represents intermediate and grade III represents intense coloration of the cells.

\section{Statistical analysis}

The results were presented for continuous variables as mean \pm standard deviation (SD), median and minimummaximum. The normality of distribution for continuous variables was confirmed with the Kolmogorov-Smirnov test. For comparison of independent continuous variables between 3 groups, analysis of variance (ANOVA) was used. Homogeneity of variances was confirmed with Levene's test. While comparing 2 groups, least significant difference (LSD) was used as post-hoc test. The statistical level of significance for all tests was considered to be 0.05. A statistical analysis was performed using the IBM SPSS v. 19 package program (IBM Corp., Armonk, USA).

\section{Results}

The results of biochemical analysis in the 4 groups are shown in Table 1 . When MDA ( $\mu \mathrm{mol} / \mathrm{g}$ protein) mean levels were compared in the study groups, a statistically significant difference was found between the groups ( $\mathrm{p}<0.001)$. In order to determine the group that made the difference, binary comparisons were made, and CG and RG-100 were found to be similar ( $\mathrm{p}=\mathrm{NS}$ ). Cisplatin-injected group and RG-50 were found to be different from each other, RG-100 and CG (for all other comparisons $\mathrm{p}<0.001$ ).

When $\mathrm{tGSH}$ (nmol/g protein) mean levels were compared in the study groups, a statistically significant difference was found between the groups $(\mathrm{p}<0.001)$. In order to determine the group that made the difference, binary comparisons were made, and CG and RG-100 were found to be similar ( $\mathrm{p}=\mathrm{NS}$ ). Cisplatin-injected group and RG-50 were found to be different from each other, RG-100 and CG (for all other comparisons $\mathrm{p}<0.001$ ).

When GSHRd (U/g protein) mean levels were compared in the study groups, a statistically significant difference was found between the groups $(\mathrm{p}<0.001)$. In order to determine the group that made the difference, binary comparisons were made and CG and RG-100 were found to be similar ( $\mathrm{p}=\mathrm{NS}$ ). When CG was compared with CIS and RG-50, it was concluded that the averages were statistically different ( $\mathrm{p}=0.002, \mathrm{p}=0.012$, respectively). When

Table 1. Antioxidant levels according to study groups

\begin{tabular}{|c|c|c|c|c|c|}
\hline \multirow{2}{*}{ Variables } & \multicolumn{4}{|c|}{ Groups } & \multirow{2}{*}{$\mathrm{p}$-value } \\
\hline & $\overline{C G}$ & $\mathrm{CIS}$ & RG-50 & RG-100 & \\
\hline MDA & $\begin{array}{c}1.3 \pm 0.4 \\
1.2(1.0-1.8)\end{array}$ & $\begin{array}{c}4.5 \pm 0.4 \\
4.5(4.1-5.1)\end{array}$ & $\begin{array}{c}2.6 \pm 0.4 \\
2.6(2.0-3.1)\end{array}$ & $\begin{array}{c}1.5 \pm 0.3 \\
1.5(1.2-2.0)\end{array}$ & $<0.001$ \\
\hline $\mathrm{tGSH}$ & $\begin{array}{c}3.6 \pm 0.4 \\
3.7(3.0-4.1)\end{array}$ & $\begin{array}{c}0.8 \pm 0.2 \\
0.9(0.5-1.1)\end{array}$ & $\begin{array}{c}1.8 \pm 0.2 \\
1.9(1.5-2.1)\end{array}$ & $\begin{array}{c}3.1 \pm 0.4 \\
3.1(2.7-3.6)\end{array}$ & $<0.001$ \\
\hline GSHRd & $\begin{array}{c}5.2 \pm 1.3 \\
5.4(3.5-6.6)\end{array}$ & $\begin{array}{c}1.3 \pm 0.2 \\
1.4(1.0-1.6)\end{array}$ & $\begin{array}{c}2.6 \pm 0.5 \\
2.8(1.9-3.2)\end{array}$ & $\begin{array}{c}4.6 \pm 1.1 \\
4.7(3.0-5.9)\end{array}$ & $<0.001$ \\
\hline GST & $\begin{array}{c}6.4 \pm 0.3 \\
6.4(6.0-6.9)\end{array}$ & $\begin{array}{c}2.1 \pm 0.3 \\
2.1(1.7-2.3)\end{array}$ & $\begin{array}{c}4.1 \pm 0.3 \\
4.1(3.7-4.6)\end{array}$ & $\begin{array}{c}6.1 \pm 0.4 \\
6.0(5.6-6.6)\end{array}$ & $<0.001$ \\
\hline SOD & $\begin{array}{c}5.6 \pm 0.5 \\
5.6(4.8-6.2)\end{array}$ & $\begin{array}{c}1.3 \pm 0.4 \\
1.2(1.0-2.1)\end{array}$ & $\begin{array}{c}2.4 \pm 0.4 \\
2.4(1.8-2.9)\end{array}$ & $\begin{array}{c}5.1 \pm 0.5 \\
5.2(4.2-5.7)\end{array}$ & $<0.001$ \\
\hline
\end{tabular}

Variables are shown as mean \pm standard deviation (SD), median (minimum-maximum); CG - control group; CIS - cisplatin-injected group; RG-50 - cisplatin and rutin 50 mg/kg-injected group; RG-100 - cisplatin and rutin 100 mg/kg-injected group; MDA - malondialdehyde; tGSH - total glutathione; GSHRd - glutathione reductase; GST - glutathione-s-reductase; SOD - superoxide dismutase. 


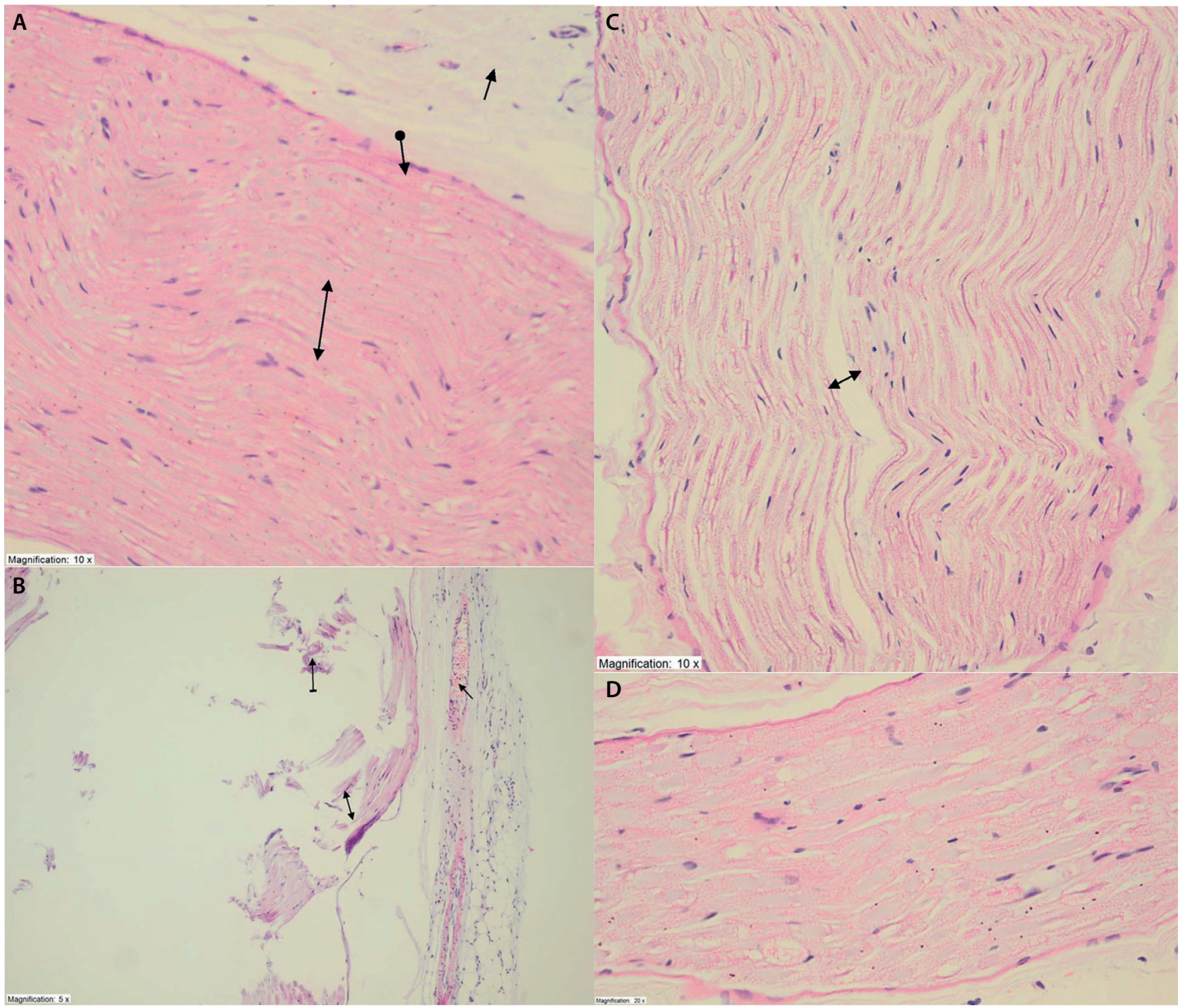

Fig. 1. A - healthy nerve tissue; the straight arrow points to the epineurium, the arrow with a circle at the endpoints to the perineurium, the two-way arrow shows the nerve fibers; $\mathrm{B}$ - CIS, destruction (arrow with a line at the end), edema (two-way arrow), dilate blood vessels (simple arrow) are seen in the nerve tissue; C - RG-50, there is only edema on the tissue (two-way arrow); D - RG-100, appearance similar to normal nerve tissue

the CIS was compared with RG-50 and RG-100, a statistically significant difference was found $(\mathrm{p}=0.006, \mathrm{p}=0.002$, respectively). When RG-50 was compared with RG-100, a statistically significant difference was found between GSHRd averages $(\mathrm{p}=0.018)$.

When the mean levels of GST (U/g protein) were compared in the study groups, statistically significant difference was found between the groups $(\mathrm{p}<0.001)$. In order to determine the group that made the difference, binary comparisons were made and CG and RG-100 were found to be similar ( $\mathrm{p}=\mathrm{NS})$. Cisplatin-injected group and RG-50 were different from each other, RG-100 and CG (for all other comparisons $\mathrm{p}<0.001$ ).

When the mean levels of SOD (U/g protein) were compared in the study groups, statistically significant differences were found between the groups $(p<0.001)$. In order to determine the group that made the difference, binary comparisons were made and CG and RG-100 were found to be similar $(\mathrm{p}=\mathrm{NS})$. When CG was compared with CIS and RG-50, the averages were statistically found to be different $(\mathrm{p}<0.001$ and $\mathrm{p}<0.001$, respectively). When the CIS was compared with RG-50 and RG-100, a statistically significant difference $(p=0.009$ and $p<0.001$, respectively) was found. When RG-50 and RG-100 were compared, there was a statistically significant difference between SOD averages $(\mathrm{p}<0.001)$.

Biochemical examinations of CG, CIS, RG-50, and RG-100 are shown in Table 1. Histopathological examinations of CG, CIS, RG-50, and RG-100 are shown in Fig. 1A-D. Figure 1A shows a healthy tissue section in CG. Figure 1B demonstrates destruction, edema and dilate blood vessels in the sciatic nerve tissue formed by cisplatin in CIS. Figure $1 C$ illustrates only edema in the sciatic nerve tissue in RG-50. Figure 1D shows similar appearance to normal nerve tissue in RG-100. 


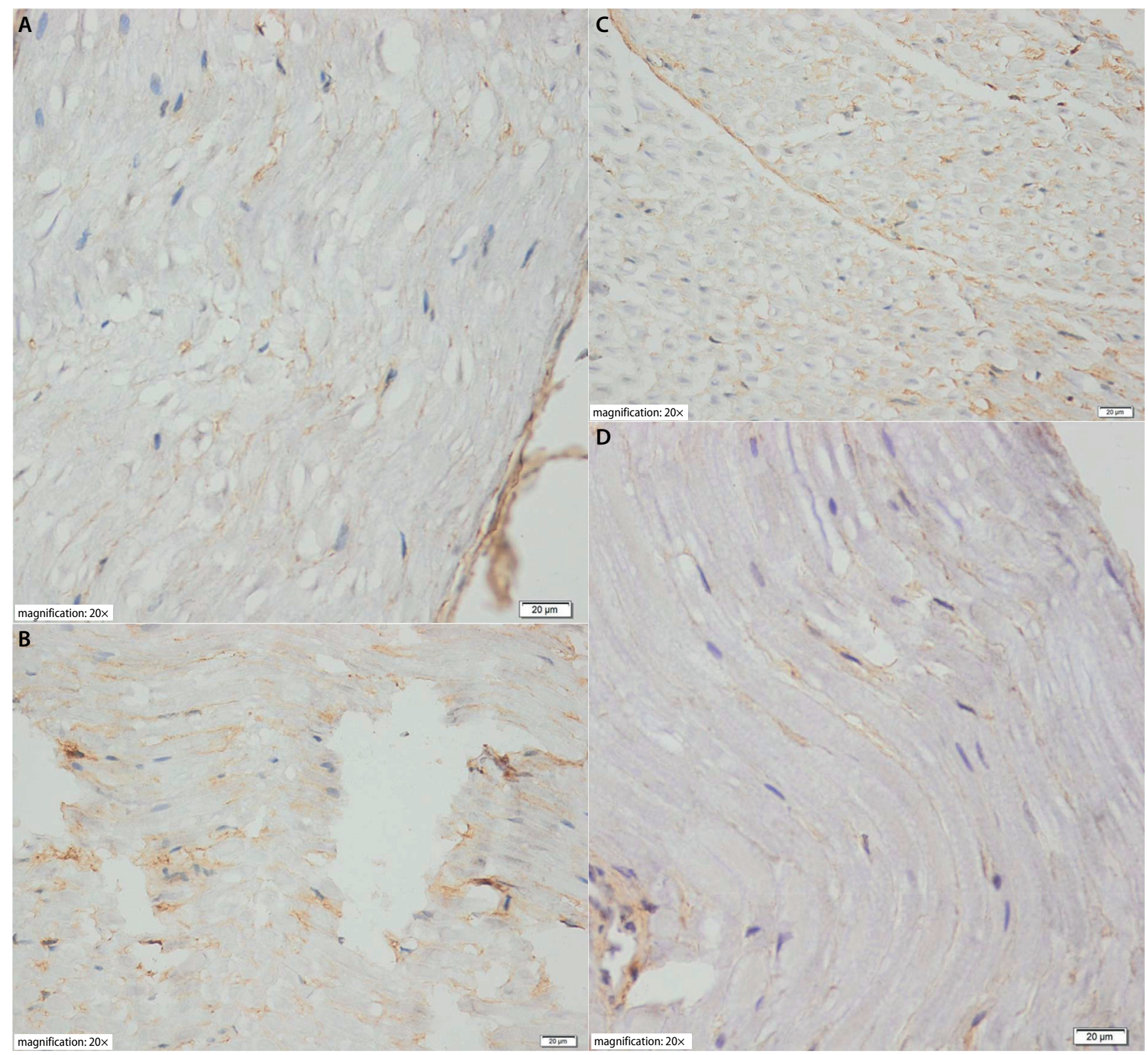

Fig. 2. A - the findings of caspase-3 expression, grade I density (mild) in the CG; B - grade II density (intermediate) in CIS; C - grade II density (intermediate) in the RG-50; D - grade I density (mild) in the RG-100

Analysis of caspase-3 expressions of CG, CIS, RG-50, and RG-100 are shown in Fig. 2A-D. Caspase-3 expression is more extensive in CIS and RG-50 than in CG and RG-100.

\section{Discussion}

The peripheral neurotoxic effects of cisplatin have been demonstrated in many studies. Neurotoxicity is the major dose-limiting side effect of cisplatin. Cisplatin increases the production of free oxygen radicals and reduces antioxidants, thereby destroying the oxidant and antioxidant balance. It also increases MDA levels. ${ }^{18}$

Rutin reduces MDA levels by decreasing lipid peroxidation. ${ }^{19}$ In the present study, a significant increase in MDA levels was observed in the samples treated with cisplatin. By contrast, significant reductions in MDA levels appeared after the use of rutin. This result is in line with the previously mentioned studies.

Total GSH levels are reduced by the use of cisplatin. Total GSH levels increase and become similar to CG with rutin (it increases tGSH activity depending on the dose). The present study is consistent with the study by Abarikwu et al., who showed that rutin had a protective effect on tGSH levels. ${ }^{20}$

Glutathione reductase is responsible for providing reduced glutathione in the cell. ${ }^{6}$ In the present study, GSHRd levels were decreased significantly in CIS compared to CG. GSHRd levels were significantly increased depending on the dose in both RG-50 and RG-100 after use of rutin. Thus, GSHRd levels in RG-100 reached similar values with 
the CG. These results are consistent with the work of Umarani et al., who observed a significant increase in GSHRd activities after application of rutin in $50 \mathrm{mg} / \mathrm{kg}$ and rutin $70 \mathrm{mg} / \mathrm{kg}$ doses to rats. ${ }^{19}$

In the present study, GST levels were decreased significantly in CIS compared to CG. Glutathione-s-transferase levels were increased in RG-50 and reached the same values as in CG with the use of rutin in $100 \mathrm{mg} / \mathrm{kg}$ dose. In one study, cisplatin caused a significant reduction of GST levels. ${ }^{21}$ In another study, GST levels significantly increased with the use of rutin. ${ }^{22}$ Both results were replicated in our experiment.

In the present study, SOD levels were the lowest in CIS and were different from CG. The use of rutin in doses of $50 \mathrm{mg} / \mathrm{kg}$ and $100 \mathrm{mg} / \mathrm{kg}$ resulted in increased SOD levels similar to those in CG. In some experiments, the use of cisplatin decreased the SOD levels in cells. ${ }^{23}$ Superoxide dismutase levels were observed to increase with the use of rutin. ${ }^{24}$ Our findings are in line with the previous data.

A histopathological examination has demonstrated that cisplatin causes toxic effects in peripheral nerves. It has been shown that these toxic effects were improved with increasing rutin doses and became similar to CG. In earlier studies, the peripheral neurotoxic effect of cisplatin in sciatic nerves had histopathological evidence. ${ }^{25}$ It has been shown that rutin reduces neuronal damage and gliosis. ${ }^{26}$

An increase in caspase-3 expression was observed in CIS as well as in RG-50. Decrease in caspase-3 in RG-100 expression was similar to that in CG. It has been shown that caspase-3 expression increases with the use of cisplatin. A decrease in caspase-3 expression was detected in experiments with animals who received cisplatin together with rutin. The present study is compatible with the study by Arjumand et al., who showed that rutin attenuated cisplatin-induced apoptosis by reducing caspase-3 expression in Wistar rats. ${ }^{27}$

\section{Conclusions}

Our biochemical, histopathological and immunochemical investigations have confirmed that cisplatin causes oxidative damage in the sciatic nerve. It has been found that $100 \mathrm{mg} / \mathrm{kg}$ of rutin reduces oxidative nerve tissue damage induced by cisplatin more significantly than $50 \mathrm{mg} / \mathrm{kg}$ of rutin. Our experimental results and the existing literature suggest that rutin is an important agent in preventing dose-limiting side effects of cisplatin.

\section{References}

1. Almutairi MM, Alanazi WA, Alshammari MA, et al. Neuro-protective effect of rutin against Cisplatin-induced neurotoxic rat model. BMC Complement Altern Med. 2017;17(1):472.

2. Akman T, Akman L, Erbas O, Terek MC, Taskiran D, Ozsaran A. The preventive effect of oxytocin to cisplatin-induced neurotoxicity: An experimental rat model. Biomed Res Int. 2015;2015:167235.
3. Chiorazzi A, Semperboni S, Marmiroli P. Current view in platinum drug mechanisms of peripheral neurotoxicity. Toxics. 2015;3(3):304-321.

4. Singh Z, Karthigesu IP, Singh P, Kaur R. Use of malondialdehyde as a biomarker for assessing oxidative stress in different disease pathologies: A review. Iran J Public Health. 2014;43(3):7.

5. Eslami S, Sahebkar A. Glutathione-S-transferase M1 and T1 null genotypes are associated with hypertension risk: A systematic review and meta-analysis of 12 studies. Curr Hypertens Rep. 2014;16(6):432.

6. Couto N, Wood J, Barber J. The role of glutathione reductase and related enzymes on cellular redox homoeostasis network. Free Radic Biol Med. 2016;95:27-42.

7. Pisoschi AM, Pop A. The role of antioxidants in the chemistry of oxidative stress: A review. Eur J Med Chem. 2015;97:55-74.

8. Nagata S. Apoptosis and clearance of apoptotic cells. Annu Rev Immunol. 2018;36:489-517.

9. Nassiri-Asl M, Hosseinzadeh $\mathrm{H}$. Review of the protective effects of rutin on the metabolic function as an important dietary flavonoid. J Endocrinol Invest. 2014;37(9):783-788.

10. Gullón B, Lú-Chau TA, Moreira MT, Lema JM, Eibes G. Rutin: A review on extraction, identification and purification methods, biological activities and approaches to enhance its bioavailability. Trends Food Sci Technol. 2017;67:220-235.

11. Nkpaa KW, Onyeso GI. Rutin attenuates neurobehavioral deficits, oxidative stress, neuroinflammation and apoptosis in fluoride treated rats. Neurosci Lett. 2018;682:92-99.

12. Karakurt Y, Ucak T, Tasli N, et al. The effects of lutein on cisplatininduced retinal injury: An experimental study. Cutan Ocul Toxicol. 2018;37(4):374-379.

13. Ohkawa $\mathrm{H}$, Ohishi $\mathrm{N}$, Yagi K. Assay for lipid peroxides in animal tissues by thiobarbituric acid reaction. Anal Biochem. 1979;95(2):351-358.

14. Sedlak J, Lindsay RH. Estimation of total, protein-bound, and nonprotein sulfhydryl groups in tissue with Ellman's reagent. Anal Biochem. 1968;25(1):192-205.

15. Carlberg I, Mannervik B. Glutathione reductase. Methods Enzymol. 1985;113:484-490.

16. Habig WH, Jakoby WB. Assays for differentiation of glutathione S-transferases. Methods Enzymol. 1981;77:398-405.

17. Sun Y, Oberley LW, Li Y. A simple method for clinical assay of superoxide dismutase. Clin Chem. 1988;34(3):497-500.

18. Hashem RM, Safwar G, Rashed LA, Bakry S. Biochemical findings on cisplatin-induced oxidative neurotoxicity in rats. Int J Adv Res. 2015;3(10):1222-1234.

19. Umarani V, Muvvala S, Ramesh A, Lakshmi B, Sravanthi N. Rutin potentially attenuates fluoride-induced oxidative stress-mediated cardiotoxicity, blood toxicity and dyslipidemia in rats. Toxicol Mech Methods. 2015;25(2):143-149.

20. Abarikwu S, Olufemi P, Lawrence C, Wekere F, Ochulor A, Barikuma A. Rutin, an antioxidant flavonoid, induces glutathione and glutathione peroxidase activities to protect against ethanol effects in cadmium-induced oxidative stress in the testis of adult rats. Andrologia. 2017;49(7). doi:10.1111/and.12696

21. Niu C, Ma M, Han X, Wang Z, Li H. Hyperin protects against cisplatin-induced liver injury in mice. Acta Cir Bras. 2017;32(8):633-640.

22. Osawe S, Farombi E. Quercetin and rutin ameliorates sulphasalazine-induced spermiotoxicity, alterations in reproductive hormones and steroidogenic enzyme imbalance in rats. Andrologia. 2018;50(5): e12981.

23. Oz M, Atalik KEN, Yerlikaya FH, Demir EA. Curcumin alleviates cisplatin-induced learning and memory impairments. Neurobiol Learn Mem. 2015;123:43-49.

24. Patil SL, Somashekarappa H, Rajashekhar K. Radiomodulatory role of rutin and quercetin in Swiss Albino mice exposed to the whole body gamma radiation. Indian J Nucl Med. 2012;27(4):237-242.

25. Uchino H, Matsumura Y, Negishi T, et al. Cisplatin-incorporating polymeric micelles (NC-6004) can reduce nephrotoxicity and neurotoxicity of cisplatin in rats. Br J Cancer. 2005;93(6):678-687.

26. Ramalingayya GV, Cheruku SP, Nayak PG, et al. Rutin protects against neuronal damage in vitro and ameliorates doxorubicin-induced memory deficits in vivo in Wistar rats. Drug Des Devel Ther. 2017;11: 1011-1026.

27. Arjumand $W$, Seth $A$, Sultana S. Rutin attenuates cisplatin induced renal inflammation and apoptosis by reducing NFKB, TNF- $\alpha$ and caspase-3 expression in Wistar rats. Food Chem Toxicol. 2011;49(9):2013-2021. 